\title{
AN ETHICAL APPROACH TO THE IMPLEMENTATION OF BEHAVIOURAL SCIENCE IN THE DESIGN PROCESS
}

\author{
Fredrik Hope KNUTSEN \\ OsloMet - Oslo Metropolitan University
}

\begin{abstract}
This master's study touches upon the interdisciplinary potential in behavioural design in product design education. The design field is commonly known for focusing on solving the user's needs. However, behavioural design takes a different approach to understand the user by using new ways to analyse the user to solve their needs. Designers engage in devising courses of action to change existing situations into preferred ones. Through a systematic literature review on behavioural science that builds on theories and models rooted in psychology, sociology, and behavioural economics this study explores how designers can apply knowledge from behavioural science to the design process. The results show how designers can use theories and models from social psychology to enhance their abilities to understand their users on a deeper level. Account of how the mind makes decisions is a fundamental part of understanding behavioural science. Such information provided by behavioural models can assists designers in taking their solutions even further using cutting-edge research and information provided by behavioural models. This can promote new solutions by better understanding which behavioural change we want to achieve. However, insights into the behaviour of the user connects to a debate on the ethical implications this may have. The designer can affect behaviour at a certain scale. A key to preventing unethical design can be to utilise measurements and regulations methods, to prevent unintended outcomes.
\end{abstract}

Keywords: Behavioural design, behavioural science, ethics, social psychology, design process

\section{INTRODUCTION}

According to Peter Downton, design is a way of inquiring, a way of producing knowing and knowledge; this means it is a way of researching [1]. When it comes to professional practice, few designers receive formal training in research and therefore lack an understanding of what researching entails. Designers can develop as professionals with a broader and more in-depth understanding by incorporating proper scientific research into their practice. The design practice has developed further into cross-disciplinary research; this provides designers with the opportunity and motivation to explore research methods in order to complement their creative skills. Cross-disciplinary research utilises methods such as quantitative market research, personal interviews, experimental design analysis and qualitative research. This study will provide insight into how behavioural science can bring different disciplines together and enrich the designer with a broader understanding of the user [1]. Design is fundamental to solving the user's needs; according to Wendel [2], behavioural design provides a productive approach that encourages the designer to perceive the user as a solvable equation. This mindset allows the designer to further understand the user and his/her goals, which in turn provides data that can reveal details about essential design areas. Designers generally engage in devising courses of action to change existing situations into preferred ones in the design field [3]. This paper will attempt to address how behavioural design can lead to beneficial results by assessing different behavioural models and their underlying terminologies. The rationale for this study is to provide designers with the tools they need in order to help them gain insight into the user and generate successful approaches. This study has conducted research on behavioural science that builds on theories and models rooted in psychology, sociology, and behavioural economics [3]. Insight can be achieved by understanding the fundamental elements that encourage the behaviour. Elements such as habits, intentions, norms, situational influences, cues, motivation and ability are all elements that play a crucial role in how our brain makes unconscious as 
well as conscious decisions [4, 2]. However, it is vital to assess the ethical implications that behaviourchanging design might carry. The research question is, therefore: Why should the designer be aware of ethics when using behavioural science as part of the design process?

\section{METHODS}

This study utilises a qualitative approach by analysing both robust peer-reviewed theories as well as empirical data on the topic at hand. Typically, the audience would benefit from qualitative research approaches such as ethnography. However, this study will perform a case study instead and highlight the different findings through a systematic literature review[1]. The literature has been sourced from sites such as Web of Science, Google Scholar and ResearchGate.

\section{ETHICS}

A central topic for this study has been the ethical implications which behaviour-changing design presents. In this section, we will look at some ways in which the behaviour change approach falls under criticism due to ethical concerns. Behavioural-changing design encourages strategies that aim to make use of human psychology in order to benefit the service, system or product. However, this approach sometimes falls short when it comes to respecting the individual. With the wrong approach or action, we could risk harming the individual. The major problem with the behaviour change approach is that it allows and endorses manipulative strategies. We find this problem primarily in strategies for social marketing and in 'scare campaigns' [5]. We can split the unethical areas of the behavioural design into two parts. Part one is about creating behaviour from which someone else benefits by persuading, coercing or manipulating the user into something they are unaware of or benefit from. Part two is about how some strategies fail to preserve the user's right to make self-determined decisions. This is done by applying tools such as persuasion, coercion and, especially, authority. Since the goal is to discuss the ethical considerations, this paper will only focus on part two. This is in order to avoid the promotion of ethically questionable strategies such as persuasive technology, used to trick or coerce people into pushing a specific button on a page. Ethical considerations are something designers are encouraged to reflect upon when making their design decisions. The guidelines by Berdichevsky and Neuenschwander's 'Figure 1' were created in a society where other cultural conditions were considered, such as current social factors, policies, and other cultural events from that time. Guidelines created 10 or 20 years ago become less relevant as technology and social conditions change. According to an MIT technology review, even ethics have a hard time keeping up with the rapid development of technological advances [6]. However, in 1999 Berdichevsky and Neuenschwander developed a guideline which builds on how individuals have developed as participants in society. Dr Leyla Acaroglu says: 'Ethics is not a given; it has to be constructed by the participants of society. What we get and what we don't get is decided by implicit and explicit actions to agree or disagree with the status quo of the day.' [7]. As illustrated in Figure 1, Berdichevsky and Neuenschwander has developed a map showing responsibility of intended and unintended outcomes to analyse whether designers could be considered morally responsible for the ways in which their products/services/systems are used [4].

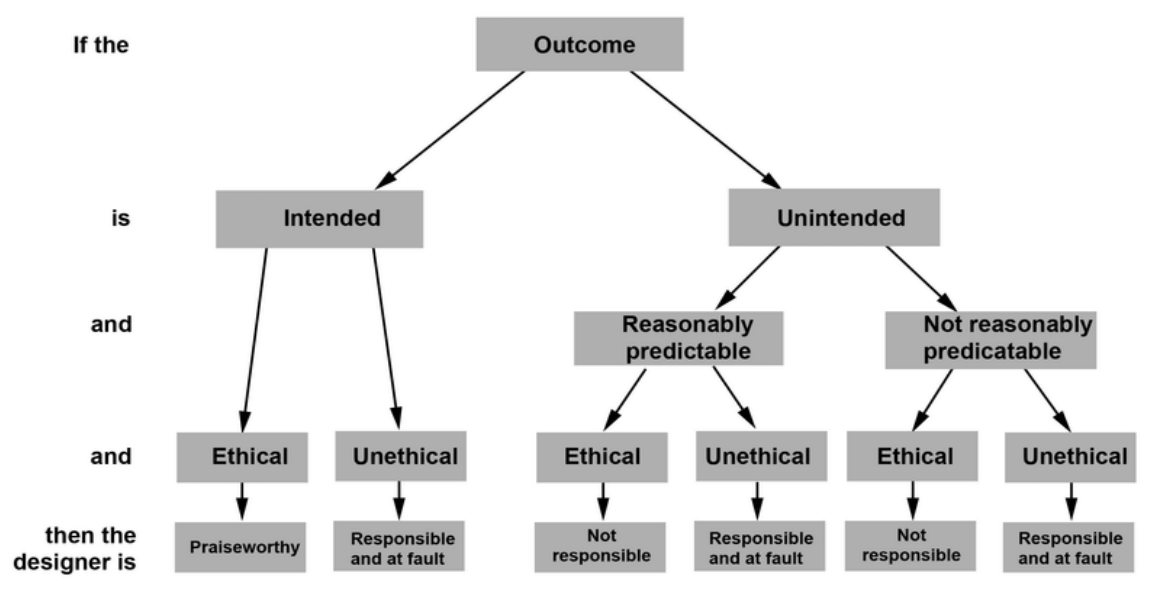

Figure 1. Responsibility of intended and unintended outcomes 
Jen Gispen produced a toolkit called 'ethics for designers' to help designers incorporate ethics into their design process. This toolkit presents designers with the opportunity to develop these ethical skills [8].

\section{BEHAVIOURAL MODELS FROM SOCIAL PSYCHOLOGY}

To enhance understanding of the user during the design process, designers have often adopted a method called 'empathic modelling'. Empathic modelling is generally described as 'stepping into someone else's shoes', however as described in the empathic design. The knowledge provides the designer with an enriched understanding of the user, enabling better design solutions. With behavioural models from social psychology, designers can have the opportunity to enhance their abilities to understand their users at a deeper level [9]. Understanding the models from social psychology requires an understanding of their terminologies. For the sake of interdisciplinary clarity, this study explores a few terminologies that are commonplace in social psychology models.

Our attitudes consist of cognitive, affective and behavioural components. Social psychologists reserve the term 'attitude' to refer to our relatively enduring evaluation of stimuli, and the stimuli are called the attitude object. This term originates in the theory of planned behaviour by Ajzen, which specifies the nature of relationships between beliefs and attitudes. Their accessible beliefs determine attitudes about the behaviour, whereas belief is defined as the subjective probability that the behaviour will produce a particular outcome [10]. Subjective norms is another term, which focuses on the individual's perception about a particular behaviour, and which is influenced by other group or party members such as parents, spouse, friends and teachers [11]. Perceived behavioural control is an individuals perceived ease or difficulty in performing a particular behaviour [12]. It is assumed that perceived behavioural control is determined by the total set of accessible control beliefs. An indication of an individual's readiness to perform a given behaviour. Intention is assumed to be an immediate precursor of behaviour [13]. It is based on attitudes toward the behaviour, subjective norms, and perceived behavioural control, with each predictor weighted for its importance in relation to the behaviour and state of interest.

Compared to Ajzen's theory of planned behaviour, the comprehensive action determination model (CADM) 'Figure 2' is directly determined by influences from three possible sources: habitual, intentional and situational. The habitual process tells us how the mind takes shortcuts by utilising schemata, heuristics and associations. The intentional processes are similar to the intention from the theory of planned behaviour, which is composed of intentions, attitudes and beliefs. According to Klöckner and Blöbaum, these are interconnected in a hierarchical structure: intention - attitudes beliefs [4]. The situational influence is an underlying foundation, which affects the habitual, intentional and normative processes as well as behaviour with subjective and objective constraints. The normative processes consist of personal norms that are affected by subjective/social norms and values. This predictor has an indirect effect on behaviour by affecting habitual and intentional processes [4].

Attempts to investigate and understand behaviour in different contexts have resulted in different theories. Two particular theories create a better understanding of behavioural science, namely Ajzen's theory of planned behaviour and the comprehensive action determination model. According to Wendel's book Designing for Behaviour Change, Ajzen's theory of planned behaviour focuses on how our intentions to act are formed. It is a product of attitudes, norms, and perceived control over the behaviour [2]. Jan Egil Nordvik states that this model has been used by governments for several years to produce preventive health information campaigns. The premise of Ajzen's theory of planned behaviour is intention, but intention does not always lead to behaviour [14]. Klöckner and Blöbaum CADM refers to intention, context and habits as fundamental parts of behaviour [15]. The difference between Ajzen's theory of planned behaviour and CADM. Is that Klöckner and Blöbaum have included more predictors of behaviour, such as a habitual process, where they introduce habit strength as a third predictor of behaviour. When we look at how Ajzen presents his theory: attitude + subjective norms + perceived behavioural control = intention, where the intention is the only predictor leading to behaviour. In Figure 2 it can be seen how CADM builds on a model comprising four different predictors of behaviour: normative processes, habitual processes, intentional processes and situational influences. The normative process is about how social norms, personal norms, awareness of need, and awareness of consequences, affect behaviour. The situational process is about constraints; it is often identified as perceived behavioural control. The habitual process is about how behaviours are performed with a minimum of cognitive effort $[15,4]$. 


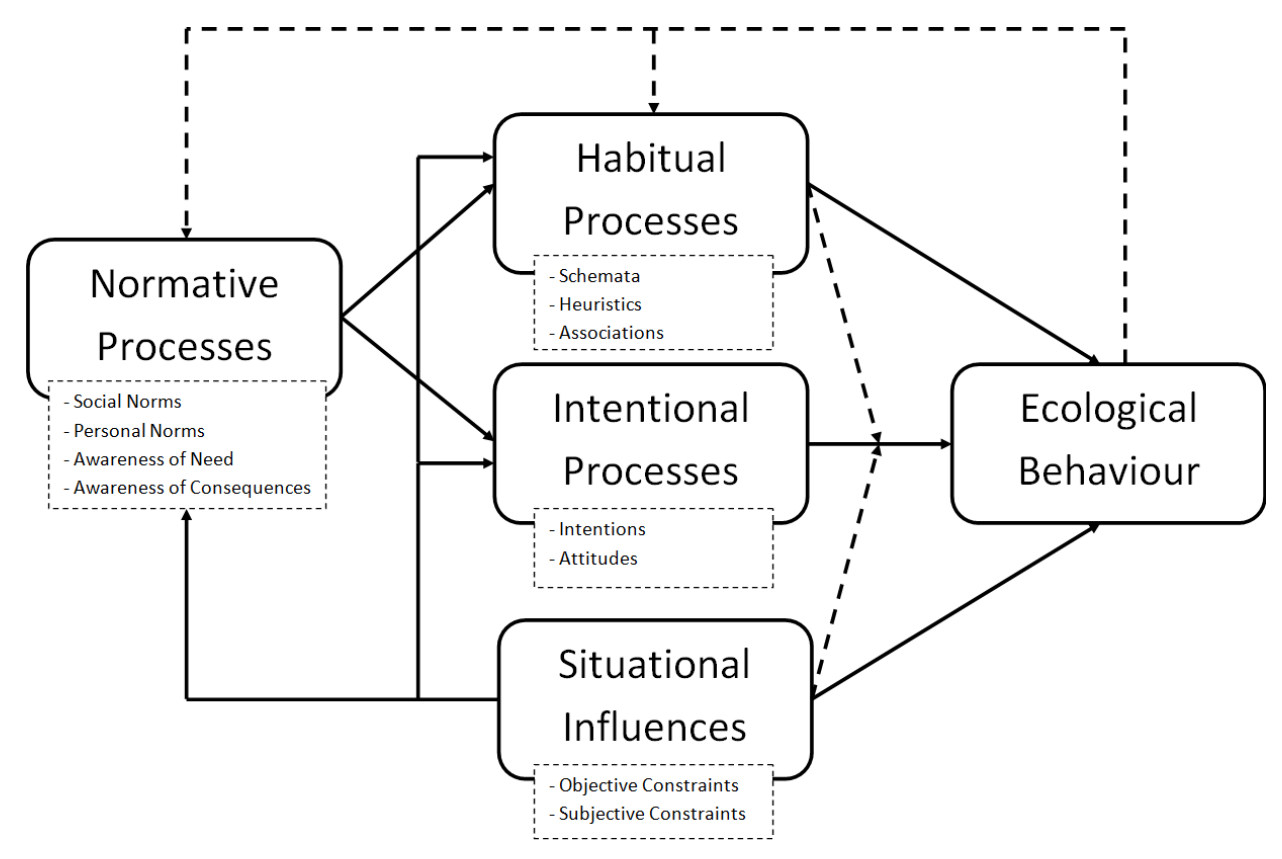

Figure 2. Comprehensive action determination model

\section{BEHAVIOURAL TOOLS}

Insight into how the mind makes decisions is a fundamental part of designing for behavioural change. This study includes implementing and improving the design methodology, double diamond, which is built on four stages: discover, define, develop, and deliver. According to the Design Council, the creators of the double diamond state that it is a design methodology that has become a reference tool for millions. This is due to the common perception that design is not a linear model, where following the design methodology from A to B guarantees results. Bela Banathy proposed a divergence-convergence model in 1996, which was later updated by the Design Council to add more structure to it. The Design Council recently updated the double diamond, which is now called a framework for innovation. It builds on the old model with a few updates on changes which design is undergoing, such as adding design principles. These four principles are: 1) put people first, 2) communicate visually and inclusively, 3) collaborate and co-create, and 4) iterate, iterate, iterate. The first principle stands for shaping an understanding of the people using a service, their needs, strengths, and aspirations. The CADM is therefore an excellent tool to implement in the discovery phase, which is the first diamond. The discovery phase helps designers to understand the user rather than assuming what the problem is, and includes methods such as primary and secondary research, which involve speaking to and spending time with people who are affected by the problems the designer is studying [16]. CADM will help influence minds and shape behaviours due to the way it promotes a better understanding of human psychology. This will result in insights into why people do what they do. With insights like these, designers can improve their product, service or system with better ideas that the user will not even know they desire, due to more collected data on where to search for solutions. This will eventually lead to better solutions because we know which behavioural change we want to achieve. With the quest for gaining insight to design solutions with a lasting and positive impact on people's lives, we must ensure that our methods are used ethically.

\section{ETHICAL IMPLEMENTATIONS}

The World Design Organization (WDO) has developed a code of professional ethics. These ethical guidelines are designed to advance the quality of the industrial design profession and can be used for most design disciplines. Back in 2013 when WDO was known as 'ICSID', article two stated 'the role of a designer as one that does not harm or contradict the wellbeing of a user, however, without a deep understanding of the user this is impossible. To understand what 'harm' or 'benefit' means, one has to understand the person, thus, without empathy, any code of ethics may remain dependent upon designers' superficial assumptions.' [9]. With that in mind, the ethical guidelines should be implemented in the development and delivery phases since this is where the designer's insights are translated into ideas. Using Berdichevsky and Neuenschwander's map 'Figure 1', designers can test whether their 
concept/product is considered ethical or unethical. However, it is essential to state that designer cannot be held responsible for all of the impact, since they do not make every decision themself, even though they play a significant role in the development of the final outcome [4].

\section{IMPLICATIONS FOR PRACTICE}

This research consists of insight into how behavioural science can give designers a broader understanding of their design problem. The ethical implications may be challenging to address because design ethics is a topic that has received little attention. This is in addition to a lack of discussion on the topic in the design field. It has been developed some guidelines designers can incorporate into their practice, as suggested in the text. Berdichevsky and Neuenschwander's map to analyse whether designers could be considered morally responsible is an excellent way to test whether a particular design is something the designer finds suitable. Nevertheless, it will not provide insight into faulty areas or how to prevent wrong choices. Jen Gispen's toolkit called 'ethics for designers' would make it easier to spot where in the design process the wrong choice was made. Further studies can dig deeper into how the toolkit could improve design practice, because when it comes to behavioural models, the best models have not yet been adopted. However, the models presented here brings up an important understanding of behavioural models and their underlying terminologies. The selected models were considered to cover the most critical factors, to understand how our intentions are formed. There is often an abundance of behavioural models in product design education, such as Dugg's Habit Model, Fogg's Behaviour Model, the Hooked Model, Self-Determination Theory and so on. However, Ajzen's theory of planned behaviour and the comprehensive action determination model stand out for their similarities as well as for their differences. By incorporating one of these models into the discovery phase, the designer may benefit in all sub-disciplines. This is relevant in many design disciplines because those benefits may also be cross-disciplinary.

\section{ACKNOWLEDGMENT}

I am very grateful to Amir Ezat for his help with the terms and concepts in social psychology.

\section{REFERENCES}

[1] Muratovski G. Research for Designers: A Guide to Methods and Practice. 1st ed. Johanneshov: SAGE; 2016.

[2] Wendel S. Designing for Behaviour Change. 1st ed. [Place of publication not identified]: O'Reilly Media, Inc.; 2013.

[3] Mahamuni R., Khambete P., and Punekar R. Behaviour Progression Framework for Designing Sustained Behaviour Change. Smart Innovation, Systems and Technologies. 2019; 39-50.

[4] Daae J. Informing Design for Sustainable Behaviour. NTNU Open. 2014, pp. 46-60.

[5] Tengland P. Behaviour Change or Empowerment: On the Ethics of Health-Promotion Strategies. Public Health Ethics. 2012, 5(2):140-153.

[6] Waadhwa V. Laws and Ethics Can't Keep Pace with Technology. Available: https://www.technologyreview.com/2014/04/15/172377/laws-and-ethics-cant-keep-pace-withtechnology/ [Accessed on 2020, 17 October], (2014) 15 April.

[7] Acaroglu L. How Design Designs Us: Part 3 | The Ethics of Design. Available: https://medium.com/disruptive-design/how-design-designs-us-part-3-the-ethics-of-designca40e33f5842\#.5ur28he4l. [Accessed on 2020, 15 October], (2016) September.

[8] Gipsen J. Ethical tools for designers. Available: https://www.ethicsfordesigners.com/tools [Accessed on 2020, 15 October], (2017).

[9] Barnes V. and Du Preez V. Mapping empathy and ethics in the design process. Design Education Forum of Southern Africa. 2015, pp. 1-10.

[10] Ajzen I. and Fishbein M. A Bayesian analysis of attribution processes. Psychological Bulletin. 1975, 82(2):261-277.

[11] Amjad N. and Wood A. Identifying and changing the normative beliefs about aggression which lead young Muslim adults to join extremist anti-Semitic groups in Pakistan. Aggressive Behaviour. 2009, 35(6):514-519.

[12] Ajzen I. The theory of planned behaviour. Organizational Behaviour and Human Decision Processess. 1991, 50(2):179211. 
[13] Ajzen I. Perceived Behavioural Control, Self-Efficacy, Locus of Control, and the Theory of Planned Behaviour1. Journal of Applied Social Psychology. 2002, 32(4):665-683.

[14] Erlandsen H. Designing Behaviour - Using Behaviour Theory in Designing for Welfare Technology. ADORA AHO. 2017, pp. 52-62.

[15] Banwo A. and Du J. Workplace pro-environmental behaviours in small and medium-sized enterprises: An employee level analysis. Journal of Global Entrepreneurship Research. 2019, $9(1)$.

[16] What is the framework for innovation? Design Council's evolved Double Diamond. Available: https://www.designcouncil.org.uk/news-opinion/what-framework-innovation-design-councilsevolved-double-diamond. [Accessed on 2020, 18 October], (2019). 